\title{
Integrating learning experiences across tertiary education and practice settings: A socio-personal account
}

\author{
Stephen Billett, Griffith University, Australia
}

There is growing interest by governments, industry, students and employers in providing tertiary education students with experiences in practice settings (i.e., workplaces) and then integrating those experiences into their educational programs. Yet, the bases for organising and securing such integrations remain unclear. There are quite diverse explanatory accounts about what constitutes such integrations and, therefore, how they might be best enacted and supported within tertiary education. These accounts often differ through their privileging of particular emphases in their conceptualisations. One emphasis is on the qualities and characteristics of each physical and social setting (i.e., workplace and tertiary educational institution) and their potential contributions to students' learning, and reconciling what arises from experiences in each of these settings. Another privileges individuals as meaning makers and their reconciliation of what they experiences in these settings. Advanced here is an account that acknowledges and reconciles these two emphases. This explanatory account comprising a duality that emphasises both what each setting affords students, on the one hand, and, on the other, how learners elect to engage, construe and construct from each setting and then reconcile those experiences as directed by their interests, capacities and cognitive experience. This socio-personal explanation is supported by literature emphasising the contributions between the mediations of social and physical world, and individuals' construing and construction of them, but also the relations amongst them. Having discussed this account as a means to understand the process of integrating those experiences, some considerations of curriculum, pedagogy and epistemological factors are advanced.

\section{Integrating experiences across education and practice settings}

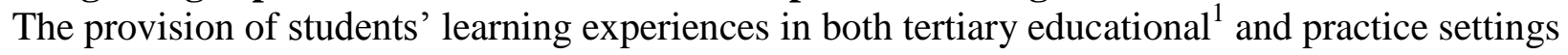
(i.e., workplaces) has long and seemingly effectively served societal and personal needs for developing occupational skills and capacities. These arrangements have likely been the most long standing in medical and legal education (Elias, 1995), and through 'modern' forms of apprenticeships implemented since industrialisation in many nation states (Deissinger, 2002). The provision of workplace-based experiences have also been extended more recently in a greater range of education programs with specific occupational focuses, such as in the cooperative education movement in North America (Ricks, 1996). There are also well-established provisions of these experiences in teacher and nurse education programs, and now for many other occupations, particularly in, but not restricted to, the health-care sector. Yet, whilst the provision of workplace experiences has now become widely adopted, the intentional integration of the two sets of experiences for specific educational purposes is not so commonly practiced. Indeed, many initiatives in contemporary times, whilst explicitly emphasising the provision of work experience, appear less concerned with the integration of those experiences. Deliberate efforts to integrate work experiences in contemporary tertiary education appear to be first attempted within the Northern American cooperative education movement through the use of specific pedagogic practices to achieve this outcome: the co-op seminar (Grubb \& Badway, 1998). Yet, for the government driven reforms that are emphasising the inclusion of work experiences in tertiary education need to be realised through actions based on a comprehensive explanatory account of what constitutes such an integration and how it might be enacted. Offering such an account is the focus of this article.

\footnotetext{
${ }^{1}$ Tertiary education here refers to that which is beyond compulsory schooling and includes university and vocational education, as well as provisions of apprenticeship arrangements when they are post compulsory education.
} 
Certainly, there are diverse sets of explanatory accounts of what constitutes such integrations, and how they might be best realised in educational programs (Eames \& Coll, 2010; Tynjala, 2008). Given the diversity of these accounts and distinct emphases within them, it is difficult to identify and enact the kinds of curriculum and pedagogic practices required to secure their intended educational purposes (Grollman \& Tutschner, 2006; Stenstrom et al., 2006). Consequently, this review seeks to identify and articulate accounts of what might constitute such an integration of experiences and learning across both settings. It does this from offering perspective from two polar perspectives and then attempts a reconciliation of them. This reconciliation is informed by conceptions and theories of learning that provide helpful insights into how the integration of experiences across educational and practice settings might be explained and used to assist tertiary students' learning. Well-traded terms such as 'transfer' and 'adaptability' provide bases to explain the integration process from a cognitive perspective, when these are seen as taking knowledge from one situation and applying it to another. Yet, this kind of transfer is often used to refer to quite novel experiences, held to be quite limited and occurring infrequently given its demanding nature (Stevenson, 1991). Indeed, this very lack of transfer of learning from experiences in educational institutions is one reason why there is a growing interest in providing practice-based learning experiences in educational programs (Organisation for Economic Co-operation and Development (OECD), 2010; Raizen, 1989). However, the integration of experiences in two settings is probably not best conceptualised as a process of transfer, because of its implications of transferring something from one place to another, as Lave (1991) critiqued long ago. Instead, transfer itself is more closely associated with students' learning arising from them negotiating and reconciling what they have experienced across two distinct kinds of physical and social settings (Billett, 2013). These negotiations and reconciliations necessitate accounting for contributions to learning arising from engaging in distinct kinds of activities and interactions afforded in each of these settings, how students are able to participate in them, and bases through which these processes of reconciliation arise as learning for students.

As is elaborated and discussed below, one approach to explain such integrations or reconciliations is to identify the characteristics and potential contributions of both the educational and practice settings to students' learning, and then align them with what needs to be learnt for the occupational practice that is the target for the educational provision. That is, identifying how and what each setting can contribute to achieving the particular educational purposes and then construct the curriculum and pedagogic means to utilise and integrate those contributions effectively. From this perspective, these settings are viewed as being objective physical and social environments that have particular activities and interaction that will potentially afford and yield to students' specific forms of knowledge (i.e., the kinds of knowledge utilised and accessed in each setting). The assumption here is that what is accessible and suggested in each setting is unequivocal and unambiguous. What is required in this account is for students to appropriate and integrate what is accessible in each setting. At its simplest, it is popularly held that 'theory' arises in educational settings and 'practice capacities' in work settings. The purpose of providing workplace experiences is, therefore, to link these two forms of knowledge that have sources in distinct social environments. So, procedurally, it may be suggested that experiences in the two settings will furnish students with the knowledge required for effective occupational performance. However, such a view is simplistic and incomplete.

Then, conversely, there are accounts of these integrations that strongly privilege students as active constructors of their knowledge that is accessible in each setting and their role in integrating what has been experienced (and learnt) in both settings. This view is premised on individuals' processes of construing and constructing knowledge (i.e., learning) from what they experience. In this account, learners' process of 'experiencing' is emphasised and seen in terms of how they subjectively construe and construct knowledge from what they experience in and across the two settings. Here, students' cognitive experience (Valsiner, 2000) and their interests, intentionalities and direction of their experiencing (Malle, Moses, \& Baldwin, 2001) are central to how and what is learnt within and across these two settings. This third way proposed here offers an accommodation 
of both approaches and is advanced as a socio-personal conception of experiences and experiencing and positioning integrations as personally-mediated reconciliations. This approach proposes a relational duality between the contributions of the settings (Billett, 2008) and how individuals construe what is learnt through and across experiences in these two settings. It also accommodates the limits and perils of accounts based on either the social suggestion or the personal construction (Miller \& Goodnow, 1995). Procedurally, this account of integration includes considerations of what each environment can potentially and should afford students, yet also how students need to actively engage in, learn through and reconcile these experiences, albeit in personally distinct ways. Yet, these affordances and these engagements will need to be organised and enacted in ways directed towards and optimising opportunities for achieving the kinds of outcomes required from such programs. This socio-personal account is offered to provide a comprehensive explanation of what constitutes these integrations and how they might be most effectively promoted within educational provisions.

\section{Work-based imperatives}

As noted, regardless of the tertiary educational sector, a key contemporary educational purpose is for students to learn applicable occupational knowledge from the contributions of both education and workplace settings, buoyed by the belief that each has the potential to offer distinct contributions to students' learning (Tynjälä, Välimaa, \& Sarja, 2003). Concerns about school leavers' ability to secure employable skills through their schooling experience have driven the OECD Learning for jobs (2010) report demanding workplace learning experiences to be widely available for young people to develop these capacities and, thereby, support productive and smooth transitions from study to work. Students not being able to access these kinds of experiences are probably rightly held to be disadvantaged in developing the capacities required for the transition to work and performance in work life. For instance, Symonds, Schwartz and Ferguson (2011) claim that while these options are widely available to those being prepared for high-status professional occupations in the US, they are not available to students in vocational education programs, who are in greater need of such experiences and their outcomes. So it is for these reasons that there is widening and growing interest for these kinds of arrangements to be enacted across tertiary education provisions (i.e., university, technical and vocational education) to meet graduate employability goals. Moreover, with increased emphases on occupationally-specific programs in higher education have come associated expectations that graduates from these programs should be able to move smoothly into being able to effectively practice their chosen occupation (Department of Innovation, 2008; Universities Australia, 2008). Such expectations are now leading to increasing numbers of university students engaging in work or practice-based experiences ${ }^{2}$ as part of their degree programs. This trend is evident in the United Kingdom's Foundation Degree initiative, through work-integrated learning (WIL) and service learning provisions in Australian universities, and cooperative education programs of different kinds elsewhere in community colleges, polytechnics and universities in New Zealand, Canada and the United States (Coll \& Zegwaard, 2011). These workplace learning experiences are referred to variously as teaching practicums, clinical placements, industry placements, cadetships, internships etc. Nevertheless, these workplace experiences differ in form, purpose, duration and circumstance, and the degree by which they are supported within the educational institution and workplace settings.

As already noted, many of these arrangements have long been part of higher education provisions in disciplines such as medicine, nursing, education and law. However, higher education students in a host of other disciplines are now being engaged in workplace experiences as part of their studies and an expectation that these will become key elements of and be integrated into their program of study. Consequently, commensurate effort and resources are being expended by tertiary education institutions and students to secure workplace experiences for students, and these become

\footnotetext{
${ }^{2}$ Not all of these experiences are located within physical workplaces, hence the use of the term practice-based experiences. For instance, midwifery students' follow-through experiences arise through the students engaging with birthing women across their prenatal phases and these interactions do not occur in birthing workplaces.
} 
seen as being desirable, and even essential, elements of higher education (Tynjälä, et al., 2003). So, beyond providing students with access to practice-based experiences, there is also the need for the learning arising from those experiences to be effectively integrated in students' programs to realise these programs' intended educational purposes and expectations. Yet, achieving these outcomes likely requires intentional structuring of those experiences and use of particular pedagogic practices to make explicit the links between what is learnt in both settings and their alignment with what the students are supposed to be learning to meet their programs' objectives (Billett, 2009c). The intentions of securing smooth transitions to practice and 'job ready' graduates, moreover, also requires students to actively and constructively engage in utilising and reconciling their experiences through making associations between what they experience in the two settings. So, the allocation of both institutional effort (i.e., organisation of experiences and their enrichment), and effortful engagement by students will be needed to optimise these tertiary education goals. However, such efforts need to be guided by clear conceptualisations, so that investment in educational resources and students' efforts are well-directed.

\section{Conceptualising the integration of learners' experiences}

A starting point for conceptualising the integration of learning experiences is the premise that learning arises through individuals' experiencing; and that learning is nothing other than change within individuals arising through that experiencing (Gardner, 2004). Through ongoing interactions between individuals and the social and physical world that they encounter, experiences continually arise from which we learn and all of the time (i.e., micro-genetically). These experiences are constituted by what is suggested to individuals by these worlds beyond the skin (Wertsch \& Tulviste, 1992), on the one hand, and how they come to construe those experience, engage with and change as a result of that experiencing, on the other (Billett, 2008). That change in individuals (i.e., learning) can comprise the verification, reinforcement, refinement or further honing of what individuals already know, can do or believe. This kind of learning arises continually through individuals' conscious engagement with the world beyond them through micro-geneses (i.e., moment-by-moment learning) as they experience it and through everyday activities and interactions that are familiar or routine for them (Lee \& Roth, 2005). Alternatively, by degree, these microgenetic changes can comprise new understandings, beliefs and ways of doing things arise through experiences that are novel to individuals. In particular, these novel experiences have the capacity to extend their knowledge in particular ways and through particular kinds of experiences that would not have occurred if they had not had that kind of experience (Billett, 2003).

So, individuals' experiencing and learning co-occur, as they comprise the same cognitive process. In this conception of learning through experience, what is often referred to as transfer or adaptability arises, with routine experiences comprising 'near' transfer (i.e., adapting what is known to something similar to what is known) and with non-routine experiences comprising 'far' transfer (i.e. adapting what is known to something which is quite dissimilar from what is known) (Voss, 1987). All of these processes, albeit labelled learning, transfer, adaptability or integration, have common qualities of individuals experiencing something, aligning and reconciling what has been experienced earlier and with a legacy of change in their knowledge and ways of knowing (Billett, 2013). These concepts are most commonly aligned to the human cognitive processes of perceiving, acting and introspection (Barsalou, 2008). Yet, such experiences and learning (i.e., experiencing) are by degree person-dependent because what is experienced and learnt is shaped by how individuals construe and construct what is experienced, premised on their earlier or pre-mediate experiences (Valsiner \& van der Veer, 2000). Put simply, what for one individual will be a novel experience, for another is a familiar experience, because of differences in what they have experienced and learnt previously. So for the former, the legacy can be the generation of new insights or capacities, whereas for the latter it is reinforcement or refinement of what they already know.

Hence, the experiencing and reconciliation what is encountered in two physical and social settings is shaped by individuals' ways of knowing and cognitive experience, albeit in persondependent ways and dialogically (Akkerman \& Bakker, 2011). Thus, the linking of experiences in 
educational and practice settings is likely to be quite personally-distinct across a cohort of students. For instance, experienced enrolled nurses entering an undergraduate nursing degree often have very different bases for construing and constructing knowledge about nursing from what they experience in the university program, than school leavers entering the sane degree program without clinical experience (Newton, Billett, \& Ockerby, 2009). Moreover, how they each come to associate and reconcile what has been experienced and learnt in each setting was also person-dependent, by degree (Newton, Kelly, Kremser, Jolly, \& Billett, 2009). So, while there may be intentions within educational programs and actions of educators for students to have particular kinds of experiences, including those attempting link those in two distinct settings, these will always be subject to individuals' construction of those experiences. As the social phenomenologist Schutz (1970) proposes:

Within the common environment, any subject has his particular subjective environment, his private world, originally given to him and him alone. He perceives the same objects as his partners but with adumbrations dependent upon his particular Here and his phenomenal Now (sic). (1970 p. 165)

This process of associating and reconciling experiences is helpful in explaining what might constitute integrations between education and practice (i.e., workplace) settings. That individuals may attempt and, by degree, be successful in linking what they already know with what they experience and then attempt reconciliations between them is well established in the psychological literature, but also others. For instance, Piaget (1968) referred to individuals seeking to overcome disequilibrium (i.e., an experience they cannot readily accommodate) by reconciling what they know with what they experience, thereby seeking to secure equilibrium. More recent constructivist accounts, such as those of Van Lehn (1989) and von Glasersfeld (1987), refer to a similar phenomenon they call viability: the process individuals use to make what they experience viable in terms of what they already know. Also, as a social phenomenologist, Schutz (1970) analogously refers to the process of typification in which new experiences are ordered on the basis of how individuals have come to already typify what they experience with what they know. Seemingly similar also is Vygotski's account of subjectification - of individuals translating social experience subjectively (Papadopoulos, 2008). The sociologist Giddens (1991), analogously, refers to individuals seeking to realise ontological security through their encounters with the social world. Finally, the strongly socially-oriented learning theorist Gergen (1994) makes reference to individuals drawing upon their personal histories and understandings that arise through it, when making sense of what they experience in the present moment. He proposes that as people move through life:

...the domain of relationships typically expands and the context of any given relationship typically changes. In effect, we are continuously confronted with some degree of novelty--new contexts and new challenges. Yet our actions in each passing moment will necessarily represent some simulacrum of the past; we borrow, we formulate, and patch together various pieces of preceding relationships in order to achieve local coordination of the moment. Meaning at the moment is always a rough reconstitution of the past, a ripping of words from familiar contexts and their precarious insertion into the emerging realisation of the present. (Gergen, 1994, pp. 269-270)

Although arising from distinct theoretical traditions, these accounts are quite consistent with and premised on the idea that humans are active meaning makers and constructors of knowledge that arises through their experiencing (i.e., micro-genetically), albeit premised on what they have previously experienced and learnt. Yet, the degree by which individuals are compelled to secure equilibrium, viability, typification or ontological security and exercise their effortful engagement to do so will be premised on their interest, desire and energy (i.e., their personal epistemologies). 
The process of associations and reconciliations required for the integration of experiences in education and practice settings are consonant with what is described in these conceptual accounts of learning (e.g., securing equilibrium, viability, typification, subjectification) and comprise a negotiation between individuals' cognitive experience (Valsiner, 2000). What is experienced is projected through and by the suggestions, norms and forms of the physical and social world. It follows, therefore, explicating the integration of experiences in educational and practice settings requires accounting for the active process by students making associations and realising reconciliations between what they know and experience. In this way, the process of linking and reconciling experiences in different settings - referred to here as integration - seemingly comprises a commonplace process of human meaning making. From a consideration of crossing boundaries in social circumstances Akkerman and Bakker (2011) conclude that such negotiations are ubiquitous across the range of social practices. Hence, on its own terms, there is nothing particularly unusual about the cognitive processes underpinning the integration of experiences across different settings. However, to be effective in achieving particular educational outcomes such linking and reconciliations may need to be supported and guided by others, and engaged with effortfully by those who are learning (e.g., students).

Indeed, because these processes of associations and reconciliations are not uniform, predictable or engaged with consistently, it is important to identify factors that make them invariant. Certainly, the diverse accounts referred to above emphasise personal meaning making as mediated by individuals' agency, thereby privileging individual intentionality and effort. Yet, that meaning making may not be directed towards the intended educational outcomes or what educators are directing them towards. Clearly, there is a need to be selective about what individuals engage with because the social world's demands and suggestions are so multi-fold that individuals have to rebuff much of what is suggested to them (Valsiner, 1998) to maintain what is variously referred to as their equilibrium, viability, typification and subjectification. Indeed, as Baldwin (1894) pointed out long ago, individuals' engagement with the world beyond them is undertaken selectively because of such personal imperatives. Much more recently, Glenberg, Schroeder and Robertson (1998) note how individuals exercise that control by averting their gaze (i.e., turning their head away) when actively seeking to exclude unwelcome social suggestions, such as when they are engaging in cognitively demanding tasks. So, individuals direct their efforts and intentionality when linking and reconciling what they are experiencing or have experienced, and do so selectively. In sum, these processes of integrating experiences present as processes of forming associations between what people know and what they experience from social suggestions and/or brute facts and reconciling them in personalparticular ways. Importantly, such an account is not a division between social and individual, or social suggestion and cognitive process. Instead, individuals' pre-mediate experiences, microgeneses and ontogenetic development (i.e., across their lives) arise through socially-shaped experiences. Indeed, to avoid these considerations descending into simple binaries of individual and social factors as underpinning such a process, it is important to be reminded that the individual is the personification of the social, not the opposite of it.

To advance this case more thoroughly, and elaborate distinctive and different accounts of this process of integration, the following sections outline three explanatory accounts of this process. Firstly, an account of integration based upon reconciling the contributions of two different physical and social settings (i.e., the educational and the practice setting) that privileges socially based accounts is discussed. Secondly, a consideration of integrating experiences from personal or phenomenological perspectives, which privilege personal meaning making, is then likewise described. Thirdly, an explanation proposing the process of integration as a duality comprising a reconciliation and accommodation of these two explanations into a socio-personal account is advanced. The purpose here is to present some ways in which these integrations are currently considered in order to advance a more integratated and comprehensive account of such integrations and how they might be supported with tertiary education programs. 


\section{A situational account of integration}

The scientific, educational and also lay discourses long made distinctions between learning arising from experiences in different kinds of social settings. For instance, Vygotsky is held to have suggested that scientific and everyday understandings arise from particular experiences: that is, those from being taught in school and, respectively, in situated everyday practice settings (Smagorinsky, 2011). Indeed, most noteworthy is the common distinctions between the consequences of engaging in educational settings and those settings in which people engage in and learn other kinds of socially derived activities, rather than being instructed. Sometimes, these are ascribed particular qualities, typically being 'formal' or 'informal learning settings'(Marsick \& Watkins, 1990), where formality is taken as the organised provision of teacherly activities intended to secure particular kinds of learning outcomes. Along with this distinction comes those associated with particular outcomes arising from these settings (i.e., theoretical knowledge from schooling settings and practice or procedural knowledge from workplaces). Much government policy and educational practices associated with the provision of work-based experiences seem based on such premises. That is, distinct learning processes occur and outcomes arise from experiences in each of these physical and social settings. Consequently, this rationale proceeds educationally along the lines of that students require experiences in both of these settings (i.e. school and workplace) to access their particular contributions (i.e. theory and practice) and these contributions also need to brought together or integrated, and work settings is where this best occurs.

Certainly, the physical and social settings where individuals engage and experience are held to potentially make specific contributions that shape individuals' thinking, acting and learning in particular ways (Barsalou, 2008, 2009; Billett, 2003). The experiences provided by educational and practice settings likely afford students quite distinct activities and interactions, and, across them, comprise countless variations of those activities and interactions. The kinds of activities in which individuals engage are held to shape or structure their cognition (Rogoff \& Lave, 1984), because the goal-directed activities and interactions required in particular settings have particular cognitive legacies (Billett, 2003). Accounts that view these settings as different social contexts and hold the process of integration to be one of contextualisation and de-contextualisation inform this perspective (Griffiths \& Guile, 2003; Guile \& Young, 2003). Some of those accounts view these settings as having physical or societal boundaries, including artefacts that situationally mediate processes that might support the integration of experiences and learning (Akkerman \& Bakker, 2011; Akkerman \& Bakker, 2012, Tuomi-Grohn \& Engestrom, 2003). Hence, these accounts emphasise the social suggestion and, in particular, those setting in which people act and their contributions to cognition, including the integration of experiences that are seen as embedded in particular social and physical settings. It follows, sharing knowledge secured in such settings requires processes to extract (i.e., de-contextualise, excise from within boundaries) and then apply it in other settings (i.e., re-contextualisation, boundary crossing). Indeed, accounts of boundaries, boundary objects and boundary crossing emphasise learning processes negotiated across two physical and social settings and individuals' placements within and on boundaries of such settings (Akkerman \& Bakker, 2011). Contributions from cognitive science also give credence to such accounts by suggesting that cognition is premised on multi-modal engagements (i.e., perceptual, motor, and introspective states) which are grounded in particular experiences, rather than being amodal representations of what has been experienced (Barsalou, 2008). Hence, within these accounts, individuals' representations of activities are generated by the physical and social contexts in which they are experienced. Therefore, each of these settings needs to be viewed as being construed as physical and social environments multi-modally, not merely as social settings where particular activities occur. When reconciled as a total set of experiences, these contributions are held to develop the knowledge required for effective occupational performance, thereby assisting the smooth transition of graduates into work roles.

As noted above, it is often claimed that educational settings privilege the generation of theoretical knowledge and practice settings generate procedural capacities (i.e., practice). Yet, a more plausible proposition is that the conceptual, procedural and dispositional knowledge of 
particular kinds will be developed from particular kinds of experiences, and, in both of these kinds of settings. Hence, although conceptual knowledge, which comprises facts, concepts and propositions, is often aligned with theory, there is little evidence to suggest that the securing and development of this kind of knowledge is restricted to occurring through experiences in educational settings alone, as it also arises through practice-based experiences (Billett, 2001b).

It follows, therefore, that the development of conceptual knowledge (e.g., theory) is not restricted to experiences in educational settings (Brown, Collins, \& Duguid, 1989; Rogoff \& Lave, 1984; Scribner, 1984). It arises through everyday access to and engagement in both kinds of settings, and likely more. The process of engaging in activities and using a range of related concepts, importantly, can lead to understanding associations amongst these concepts. It is the repertoire of experiences that individuals engage in in practice settings leading to rich associations between propositions that is central to developing higher order conceptual knowledge (i.e., deep conceptual knowledge). This is because causal links and propositional associations are built through these kinds of experiences and over time (Roth \& Roychoudhury, 1993). Thus, experiences in practice settings such as engaging in goal-directed activities, monitoring performance and appraising activities are likely to be generative of not only factual concepts, but also deep conceptual knowledge. So, proposing that theory (i.e., conceptual knowledge) or higher order conceptual knowledge arises only from engagements in academic settings is erroneous and misleading (Billett, 1994). Conversely, the development of procedural capacities -- being able to do things -- is also not restricted to what is learnt in practice settings (Anderson, 1982). The processes of engaging in activities, improving performance through practice and grasping opportunities for refinement also occur in educational settings, when opportunities to repeat activities and improve on them are provided. Certainly, there are inherent limitations associated with learning through practice or educational settings alone, such as the possibility that understanding cannot arise when concepts and purposes are not able to be made explicit or accessible (Billett, 2001b).

Some of these limitations can be redressed by experiences in educational settings, and vice versa. Hence, it is proposed that drawing upon and combining the contributions likely afforded in each kind of setting may help secure the complementarities across these experiences that will likely promote adaptable knowledge. Indeed, this outcome seems to be the rationale behind much of the contemporary interest in providing tertiary education students in occupationally specific programs with work-based experiences, to overcome the deficits of students only having 'school' based experiences that fail to develop the kinds of capacities that permit a smooth transition to practice upon graduation. However, the current interest in providing workplace experiences may also lead to heightened expectations by government, employers, professional bodies and, importantly, students that having provided experiences in practice settings for students will be sufficient for effective transitions to and performance in occupational practice. That is, those experiences will be expected to generate learning that will be applicable to other circumstances where the occupation is practised. Yet, this expectation may be unrealistic. The circumstances where graduates find employment may be quite different from those they experienced during their studies. That is, the practice settings may be quite distinct and not permit the kinds of boundary crossing or re-contextualisations that are desired by the workplaces where they find employment upon graduation. The degree by which contributions of two sets of experiences will collectively address this need and somehow limit the weaknesses of what is learnt in the other through generating the knowledge required for effective practice is probably unknowable. And, even if known, securing this transition may be quite difficult to manage. For instance, students, even when given access to the same set of activities in the same setting, are likely to engage in different kinds of experiences, and where settings are different they will likely provide particular combinations of experiences and learning that will be both situationally-specific (Billett, 2001a) and distinct from each other.

It follows, then, that despite the emphasis on situations and processes of contextualisation and re-contextualisation, boundaries and boundary crossing and even typification, all of these conceptions are premised on how individuals are able to make, or are interested in making, sense of what they experience. It is individuals - in this instance, tertiary education students - who have to 
engage in those contextualising processes, and identify and respond to boundaries of which they may or may not be aware, and whose typification may be highly idiosyncratic. That is, bases for making sense, identifying contributions and organising knowledge derived from beyond the skin, are likely to be organised in ways that assist their recall and utilisation in personally idiosyncratic ways. Hence, there can be no certainty by those organising and enacting these experiences for tertiary education students. Certainly, they will also need to make judgements about how these outcomes lead to the development of the canonical occupational knowledge and provide bases for its application to particular workplace settings, which may not be known at the time of the preparation. The point here is that integration of experiences in these accounts goes way beyond linking theory to practice, and emphasise the use and reconciliation of what is experienced in distinct social and physical settings to build and extend individuals' knowledge arising from and being reconciled for those settings.

In this account of integration, the 'enacted curriculum' -- what is enacted for students to learn from -- is a key educational focus. That is, the main concern is with the organisation of a set of experiences across both settings and curriculum and the means by which integration of these experiences would realise the outcome of developing occupational capacities, including understanding how these capacities might be applied across some of the range of settings in which graduates will be expected to practice. From this perspective, the focuses on the kinds of experiences these settings afford, and assumptions about particular contributions from activities and interactions in both education and practice settings, together provide the means for accessing the knowledge required for effective performance. Therefore, in these situated accounts, the integration of these experiences is founded on drawing upon the distinct contributions of these settings as contexts albeit shaped within particular kinds of boundaries and seeking associations, linkages and reconciliations across those situational boundaries and contexts. Consequently, worthwhile integration comprises those experiences collectively providing access to what is being learnt in both settings and then reconciling them in ways that secure the knowledge required for effective practice, including negotiating the boundaries which ascribe these contexts.

In this way, situational accounts emphasise social and physical environments as objective entities that make particular contributions. However, left unexplained in these accounts is how the reconciliations of experiences occur: that is, how students construct experiences and reconcile them when crossing boundaries (e.g. if they can recognise them) and re-contextualising what has been experienced. It also raises the procedural concern of the sufficiency of just providing two sets of experiences per se for generating the kinds of knowledge required for effective occupational practice. Instead, might there not be the need to assist with the integration of those experiences? Moreover, such an account tends to de-emphasise the subjective, intentional and cognitively unconscious bases through which individuals construe and construct knowledge, albeit within one setting, across settings, or the task before us here, of integrating experiences. So, whereas it focuses on the enacted curriculum it does not speak directly to the most important of curriculum concepts: the experienced curriculum (i.e., what learners come to construe and learn from those settings). Consequently, a consideration of how individuals construe and construct knowledge in particular settings is also warranted to inform the process of their integration.

\section{Personal bases of integration}

An alternative starting point for conceptualising engagement in and integrating experiences across academic and practice setting is to consider this process primarily from learners' perspectives. This conception emphasises humans as being active meaning-makers and constructors of their knowledge from what they experience. The conceptual heritage here is found in explanations provided by constructivist approaches, both more social and individual varieties, and phenomenology. As noted, both kinds of constructivist explanations acknowledge the central role humans play in making meaning from what they experience, although they differ in the degree by which this meaning-making is shaped by individuals' contributions or those from the social world. But, students' process of experiencing in both settings is central to explaining the process of 
integration and learning in both constructive accounts. This learner-focused perspective, therefore, holds that there can be no guarantee that what is afforded learners by a particular educational or practice setting will be appropriated (i.e., 'taken up') by them (Luria, 1976) or that learners will learn what those suggestions intend. Individuals may accept or reject what is suggested to them (Hodges, 1998), or their construals and constructions of what is afforded them in both settings may be partial, incomplete (Valsiner, 2000). Alternatively, as suggested above, they may simply misconstrue what the setting is suggesting to or affording them, for instance, they may not recognise the boundaries of which others might be aware, the norms and practices to be engaged with and how they had to be engaged with, or may be unaware of or unable to engage in the particular discourse. Importantly, in such a perspective, learners are placed at the centre of considerations for realising the integration of experiences across both settings. That is, how individuals engage with what is afforded them in both settings and if or what they seek to reconcile, reject or possibly ignore the contributions from elsewhere shape and how they integrate those experiences. In this perspective, the emphasis is on the individual engaging in and coming to know, whilst among other experiences they engage in both workplace and educational settings.

Explanations provided through phenomenology, and even social phenomenology, offer similar standpoints as noted in the section above. The phenomenological 'Now' to which Schutz (1970) refers emphasises the immediacy of experience through which the construal and construction of knowledge arises. As elaborated earlier, these processes are mediated by what he refers to as typification. The links here to other concepts such as appropriation from sociocultural theory, and accommodation and assimilation from developmental studies are obviously consonant. The emphasis within these accounts of these concepts is that they are strongly personally mediated by the workings of individuals' subjective private worlds. That is, they arise through individuals' life histories and become the means by which what is subsequently experienced (i.e., phenomenological Now) when encountering and reconciling activities and interactions in both settings. These private worlds can never be fully captured or measured, yet may explain something of the diverse ways in which personal processes of experiencing progress. The personal legacy here comprises changes in individuals' domains of knowledge, their knowledge and ways of knowing (Billett, 2009b). All of this emphasises the role of individuals' processes of ontogenetic development in the construal and construction of what is experienced, as these are the bases through which experiencing arises.

This explanation, therefore, emphasises individuals' prior or pre-mediate experiences (Valsiner \& van der Veer, 2000) and knowledge constructed earlier, shaping what and how they learn from what they experience in the two settings, and also how they elect to reconcile their experiences in both settings. More than personal histories, individuals' capacities, knowledge of particular discourses and interests all shape the intentionalities, means and effort with which they engage in these settings and reconcile what they have learnt from each. This explanation emphasises the important role individuals have in constructing knowledge and that, ultimately, these processes are, by degree, person-dependent. These processes find support in accounts seeking to explain the development of occupational knowledge, including the integration of dimensions and kinds of that knowledge. For instance, how tertiary students engage in interactions and activities in both settings can lead to the development of rich conceptual knowledge and the formation of associations between concepts and propositions that are central to the development of occupational expertise (Chi, Feltovich, \& Glaser, 1981; Ericsson \& Lehmann, 1996). Identifying and understanding causal links and associations is highly effortful: demanding (Roth \& Roychoudhury, 1993). Yet, if individuals elect not to, or are unable to, engage in such demanding cognitive processes, they may not develop depth of understanding or well-honed procedural capacities. Importantly, this kind of development is not that which arises easily from teaching or guidance by others. It is a product of individuals' effortful engagement and learning. Indeed, these and other kinds of higher orders of learning are likely to be dependent upon the level and kind of effort that individuals invest in their thinking and acting.

Similarly, with procedural development, the degree by which individuals elect to practice, monitor and develop further their procedural capacities is shaped by personal factors (Anderson, 
1993). Ericsson (2006) uses the term 'deliberate practice' to capture the effortful engagement in which individuals who are extremely highly proficient (e.g., excellent) at something intentionally engage to secure and sustain that level of performance. Salient here is the role of personal dispositions. Individuals' processes of experiencing and construction of knowledge are usually more than a cold cognitive process - a sensory or visceral reaction to stimuli. Instead, they are largely shaped by individuals' interests and emotions: their dispositions (Perkins, 1997; Tobias, 1994). It follows that issues central to individuals as shaped by their interests, intentions and sense of self, may be more likely to be engaged with effortfully than activities regarded as being uninteresting and of little worth by them. So, personal interest and intentionality plays out strongly in the processes of experiencing and accommodation (i.e., contextualisation, typification, boundary making and crossing) as discussed above. Effortful engagement will likely lead to a richer learning experience and stronger development than uninterested and unfocused participation in activities, no matter how potentially rich the affordances (Perkins, Jay, \& Tishman, 1993). Moreover, depending on the learners' readiness to participate, what they know and can construe from what they experience is central to what they will be able to learn through these experiences. A consideration of personal contributions also extends to brute factors such as weariness, alertness, fatigue and tiredness that shape the level and intensity of engagement (Billett, 2009a). Just as the social world is unable to project its message uniformly and unambiguously, as referred to above, so too individuals' processes of experiencing, including the construal and construction of what is experienced in the immediacy of the particular moment or phenomenological Now is shaped by their interest, energy, and time available, let alone willingness or ability to commit their resources to that particular process.

Yet, with placing the person centre stage comes the peril of positioning this account of learning as being too much about individuals' idiosyncratic construction of what they experience in work or educational settings. Instead, their learning processes need to engage with and secure understandings, procedures and values that have arisen over time within that occupational practice, having been shaped by what is effective and informed by considered enquiry of that knowledge. That is, students need to engage with and remake the canonical knowledge of their selected occupation through an active process of understanding, developing capacities and dispositions that have often taken generations of practice and inquiry to develop. In doing so, they variously transform, refine and hone their personal domains of knowledge, through its exercise in educational and practice settings. So, their learning is patterned by social experience albeit in person-particular ways (Billett, 2003). That is, individuals actively construe and construct from the immediate social experience, albeit in different ways and through personally particular ways. Yet, there remains an absence of a complete account of how individuals intra-psychologically engage in, construct knowledge from and integrate experiences across physical and social settings, and learn richly from them. To achieve these kinds of outcomes, considerations of the social settings and brute facts (e.g., physical strength, energy) are also required, as are the relations amongst all of these factors. So, there are limits to any certainty about the degree by which that patterning is predominantly situationally- or personally-mediated.

In all, explanations emphasising personal processes of construal and construction are central to processes of understanding integrating experiences and learning from them. Yet, as has been proposed, these acts of construal and construction are not divorced from the circumstances, both physical and social, in which these individuals act. Added to this is a need to account for the relations among the social and brute experience of both kinds of settings, how these contributions might best be organised to assist the effective sequencing, duration and securing of these contributions, and how individuals will draw from, link and reconcile (i.e., integrate) the contributions of the two sets of experiences. Hence, more fully explaining this process of integration - as linkages and reconciliation - necessarily requires an accounting of the duality comprising both the processes and contributions of both the personal and the social. The following aims to offer such a conception. 


\section{Integration as shaped by socio-personal factors: A reconciliation}

It follows from above that explanations about the experiencing and integration of activities and interactions in both settings need to account not only for the social, personal and brute contributions to these processes, but also the relations amongst them. There is a need to go beyond considering what is afforded by social settings and suggested by physical environments as objective phenomena and also personal factors to view both as being necessary, yet relational sets of factors, in explaining processes of learning from and integrating experiences across physical and social settings (Akkerman \& Bakker, 2011; Akkerman \& Bakker, 2012; Billett, 2006). That is, there is a need to account for contributions of and relations between the settings that afford particular kinds of contributions (i.e., activities and interactions), and how individuals utilise their knowledge in engaging in these experiences and, then, integrating them. In short, a socio-personal explanation is required to accommodate not only the uncertainty of what the social world projects, but also how individuals construe what is projected, and decide how they will engage with it. Hence, this third explanatory account accommodates the diversity of experiences afforded students in different kinds of work or practice settings, and educational programs, and their personal mediation and construction of what was experienced and learnt in and across these settings. What for one individual might be a highly inviting and engaging experience, which is generative of honing procedures or deepening understanding, might for another be uninviting and disengaging, with equivalent cognitive legacies. Moreover, as noted earlier, whereas one individual might be aware of these boundaries in an occupational practice and seek to negotiate activities in ways that are respectful of them, another might deliberately contravene them, whilst a third might not be aware of such boundaries and, therefore, have no reason to negotiate those aspects of their work. The kinds of activities in which individuals are invited to participate might be new and interesting for some, and very familiar, and possibly dull, boring and unengaging for others. For instance, recently, a resident who supervises medical students in an emergency facility in a major US city advised me that what his students find fascinating, engaging and sometimes overwhelmingly confronting in this ward, to him are mundane and tedious. Similarly, the affordances of social settings such as the guidance offered by more experienced workers might be greatly welcomed by some students, and seen by others as being unhelpful interference or constraints on their agency. Again, in the same medical school, students advised that the grand rounds (i.e., where a senior registrar works around the patients in the ward accompanied by medical students and nurses), which are seen as a key learning element of medical education, are too long, unengaging and not a good use of their time. They stated their time might be better spent engaging in more learning-intense activities, such as following up particular case conditions on the internet than participating in long periods of following registrars around wards. Affordances held to be of great worth by some are questioned by others, in this case those positioned as learners (i.e. tertiary education students).

Yet, there are other powerful reasons for viewing the integration of experiences as comprising a duality between both personal and social contributions. Beyond explanatory accounts are those advising about how intentional educational experiences might best progress. The organisation of these experiences is central to the purposes of the development of occupational capacities and situational competencies required for competence at work. The active process of engagement is emphasised in relations between learners and the world beyond them (i.e., beyond the skin (Wertsch \& Tulviste, 1992), so to speak). Their engagement is, however, also mediated by activities and interactions afforded in the educational and practice settings. The genius of human learning and development is found in these relations because they comprise active engagement and richness of affordances (Miller \& Goodnow, 1995). In these circumstances, the process of appropriation (Luria, 1976), or making knowledge individuals' own, comprises engaging with and reconciling the contributions from the two different settings, based on how individuals construe and construct experiences. This process of reconciliation - which is analogous to securing equilibrium, viability or ontological security - leads to changes in individuals' personal domains of knowledge as legacies of these engagements. Procedurally, the garnering of these experiences by individuals can progressively contribute to their developing the kinds of canonical and situational domains of the 
knowledge required for practising the particular occupation and in particular settings. This includes making causal associations and advancing propositions of the kind that constitute depth of conceptual knowledge. In all of this, the process through which individuals actively construe and construct (i.e., appropriate) knowledge is premised upon what they know (i.e., their cognitive experience) and have experienced (i.e., their pre-mediate experience) (Valsiner, 2000). Yet, there can be no confidence that what is afforded individuals will lead to them construing and constructing faithful representations of that is affordance.

The other key outcome arising from this process of experiencing and reconciliation is the continuity and advancement of cultural practices (e.g., occupations). Certainly, there is a need for tertiary education students to participate in programs developing occupational knowledge to secure access to and engage with the forms of occupational knowledge that have arisen through culture and history, and have been proven as effective over time and evolved through enhancements and embellishments in responding to the particular requirements for practice. Yet, the process of individual learning is, in part, socially reproductive, as it comprises the remaking of this knowledge at a particular point in time and relation to particular instances of practice, which can comprise active and critical engagement by students. Otherwise, it becomes too situationally-premised and denies engagement with broader (i.e., canonical) requirements. That is, this process would comprise active appropriation, rather than mastery (i.e. superficial compliance and reproductive learning) (Wertsch, 1991). This remaking through appropriation may well arise as students apply historicallyderived knowledge selectively and appropriately in their practices, not merely reproductively what they have learnt through their educational program, which is a key contribution of practice settings. Perhaps this is what the medical students were proposing in their preference for self-directed learning using internet sources, rather than repeatedly engaging in the grand rounds that others so valued. Indeed, the capacity to critically engage and appraise what they know will be personally premised as they encounter circumstances that offer perturbations and uncertainties. Responding critically to such circumstances is an attribute required of effective professional practitioners who are likely to engage in responding to novel tasks when conducting that work, sometimes in circumstances of relative isolation and need to find ways of addressing such circumstances. This process may commence students' engagement in authentic work activities and interactions in their practicums, where they are removed from direct guidance of their teachers, yet able to engage indirectly or directly with workplace experts. While these considerations emphasise the importance of learners' agency in constructing the knowledge to be learnt, they also acknowledge the need for guidance of social partners, situated norms and forms, and access to authentic instances of practice in assisting their construction of that knowledge. So, the personal experiencing of practice circumstances alone is insufficient.

Hence, educational responses (i.e., curriculum and pedagogic interventions) need to account for the duality between the contributions of the personal (i.e., cognitive experience, domains of knowledge) and the affordances of the settings in which they engage in activities and interactions, including informed partners who can assist and support that learning. The integration of such experiences is important in making associations and reconciliations, which are analogous to processes that many development theorists have used to explain the human response to novel experiences (e.g., accommodation, viability, typification, ontological security, boundary crossing etc.). It is through such engagements that tertiary education students will come to construct links and reconcile what they have learnt in both settings. These kinds of processes and outcomes are those most likely to generate not only the kinds of knowledge required to practice, but also the kinds of rich associations amongst them that are important for effective practice. Indeed, as Schutz (1970) advises, rather than presuming the links and reconciliations that these students make will be optimal, they may need support and guidance to secure the kinds of outcomes required for the occupation. Moreover this guidance might extend assisting becoming aware of the particular circumstances in which they were practice that occupation. Consequently, and finally, it is necessary to consider the curriculum, pedagogy and personal epistemology required to support those integrations. These concerns are taken up next in the next and concluding section. 


\section{Pedagogical, curriculum and epistemological considerations of integration}

The process of integrating students' experiences in academic and practice settings has been advanced here as a process of their experiencing (i.e., construal and construction) in both settings and including the reconciliation of these experiences as directed towards the kind of knowledge they need for effective occupational practice. Consequently, accounting for these processes needs to include the two kinds of social settings and their particular contributions, as well as the ways in which individuals engage in the process of meaning making and reconciliation. Central to this process of learning are their personal epistemologies, as shaped over time by their cognitive experiences, the domains of knowledge they have constructed and their intentionalities when engaging in activities and interactions and the subsequent responses to them. However, all of these processes will likely benefit from curriculum and pedagogic practices that promote and guide such learning (Tynjälä, et al., 2003).

In terms of curriculum as ordering of experiences in each of the two social and physical settings (i.e., education situations and workplaces), the key considerations are the sequencing and duration of experiences in both kinds of settings and the purposes that these experiences are supposed to secure. How students are positioned in these sequences of experiences (e.g., whether they are to be observers, partial or full participants) is also important. Within curriculum, considerations of participation in pathways of activities and defining and assisting learners fulfil their roles will likely secure the kinds of learning that are intended as central guiding elements. Should, for instance, students first engage in practice settings to understand something of the occupational practice, its requirements and practices, then participate in university courses? The ordering of these experiences has recently been discussed in considerations of midwifery students' learning (Billett, Sweet, \& Glover, 2013). These considerations address whether these students should engage in practice settings, including performing assessments and examinations of birthing women, only after they have had sufficient experience or knowledge of the birthing process from birthing women's perspectives. Another important curriculum consideration is the duration of these experiences and whether they should be ordered to intentionally provide students with a range of occupational experiences or experience in just one or two settings so that they can develop more cogent understandings and honed procedural skills first. Finally, whether it is necessary for students to engage in supervised instances of occupational practice, or whether other kinds of experiences are more less adequate stands as another crucial and practical consideration. What was found in a study comprising 20 projects across six universities was that, regardless of the particular educational purpose, the preference of students and those who taught them was for there to be a gradual or graduated process of engagement and participation (Billett, 2011). That is, students would first engage peripherally in work settings and with roles that allow them to observe and engage without being subject to the full demands of practice. Then, progressively, their engagements extend to more demanding and performance-premised tasks. This was seen as permitting understandings about the instance of practice, what constitutes performance within it and how to effectively engage as being bases to progressively build both competent practice and the confidence required to exercise those practice capacities. Even when overstated, this finding suggests that just being exposed (i.e., 'thrown in at the deep end') is unlikely to be the best curriculum model for securing effective integration of experiences across the two settings. Instead, a staged and purposive engagement is recommended.

In consideration of pedagogic approaches and given the personal nature of the experiencing and reconciliation of experiences in both settings, a key educational consideration may well be to provide opportunities for understandings to be articulated and shared and, hopefully, become more inter-subjective. If opportunities can be made available for concepts to be articulated, shared and elaborated with others, the possibilities are enhanced for developing a coherent set of personal associations and constructs, for deepening knowledge and for developing inter-subjectivity between more and less experienced participants. Hence, opportunities for this articulation and sharing are salient for experiences in both practice and academic settings. Pedagogic processes, such as 
organising discussion groups, clinical supervisions and learning circles, can provide opportunities for students to engage in processes that develop coherence and commonly understood conceptions and propositions are likely to be effective here (Heikkinen, Tynjälä, \& Kiviniemi, 2011). For instance, processes are likely to be helpful when students are seeking to reconcile concepts, propositions and facts that arise from their experiences in professional practice with those in their educational programs.

The focus of the project referred to above (Billett, 2011) identified and appraised the worth of group or shared activities that might best occur before, during and after tertiary education students' experiences in practice settings and across a range of professional practices. Prior to participating in placements, shared activities were found to be useful in helping students establish understandings about expectations and how they might best respond to what might turn out to be unexpected, unhelpful or confronting experiences. The findings indicate that developing agency in students as active learners and positioning them to extend their capacities through being agentic learners was central, as this form of directed and focussed learning was appropriate when direct guidance by more experienced co-workers was not always available, as is often the case in work settings. Moreover, these kinds of qualities as those required for practitioners to be directed but interdependent in their learning across working lives. Importantly, this goal included a clear understanding about what students needed to learn and know about how best they might progress during their practice-based experiences. Hence, these findings emphasise the worth of personal epistemologies directed towards securing and reconciling different kinds of learning experiences. Moreover, pedagogic activities prior to placements also formed a learning space in which students could contribute, share and appraise during their practicum experiences. So, for instance, students might be prepared and encouraged to actively engage in learning in practice settings through observation and listening, by seeking direct guidance from experts. Also, importantly, there was a need to be active and engaged in identifying links between what they had learnt in their courses and experienced in their practice settings. Also, and perhaps of the greatest salience, after the practicum experiences, tertiary education students should be provided with opportunities to articulate, share and reconcile their experiences with others, through processes that can be, but not always necessarily, guided by teachers. That is, it can be students or teacher guided. These processes should aim to make explicit links between what they have learnt in the educational setting with what they have experienced in the practice, and against the canonical occupational knowledge and situational variations they are seeking to learn. As noted earlier, the classical example of this process is the co-op seminars in the cooperative education movement in America in which students returning from practicum experiences had opportunities to share, reconcile and elaborate their understandings in a fairly structured way (Grubb \& Badway, 1998).

Clearly, it is neither feasible nor desirable for teachers to follow students into practice settings. Therefore, students need to be positioned to be self-ordered and intentional as meaning makers, having the interest and abilities to take control of their learning and in reconciling their experiences in both settings. This pedagogic concern necessarily emphasises the importance of their personal epistemologies. Yet, just as the kinds of goals which are being expected of higher education institutions are extremely tough, so, too, for the students, are the tasks of learning both the canonical knowledge of the occupation and the kinds of requirements to apply that knowledge in specific situations. This is especially the case where students may lack prior knowledge about the occupation they seek to practice, or the particular situational requirements of the specific setting. So, the promotion of student agency is vital to the rich integration of experiences. Purposeful learning is unlikely to occur without the effortful exercise of that agency by students. Key considerations in developing the kinds of graduate capacities that are required for effective occupational practice include both the role for the curriculum in organising the sequence of experiences as well as the pedagogic practice of teachers in supporting the integration of the experiences in the two settings, through reconciling conflicts and dissonances, and finding ways to direct the students' construal and construction of experiences. 


\section{Integrating experiences across tertiary education and practice settings}

In sum, this article has set out some bases to understand the need for the effective integration of tertiary students' experiences in both practice and educational settings. It has proposed that for these experiences to be designed and enacted effectively, uninformed and comprehensive account of what actually constitutes these integrations is required. To achieve this goal, two very distinct and possibly polar conceptions of processes of integration have been described, discussed and appraised and through this appraisal an account which attempts to reconcile them has been advanced. That account recognises the duality between the contributions from experiences beyond the person to how the person comes to construe and construct what they experience, and the consequences for their immediate learning and ongoing development. Central here is the idea that this experiencing and meaning making arises from both the mediation of the social and the mediating acts of the personal. So, on the one hand the simple exercise of providing experiences and instructional strategies would be insufficient, but so leaving individuals to reconcile their experiences alone. Instead, there arises the necessity for explanatory accounts and curriculum, pedagogic and personal epistemological practices to acknowledge the relations between the personal factors of construal and construction, including reconciling experiences across settings and the affordances of both kinds of physical and social settings. It is all of this which has been attempted here.

\section{References}

Akkerman, S. F., \& Bakker, A. (2011). Boundary crossing and boundary objects. Review of Educational Research, 81(2), 132-169.

Akkerman, S. F., \& Bakker, A. (2012). Crossing boundaries between school and work during apprenticeships. Vocations and Learning: Studies in vocational and professional education, 5(2), 153-173.

Anderson, J. R. (1982). Acquisition of cognitive skill. Psychological Review, 89(4), 369-406.

Anderson, J. R. (1993). Problem solving and learning. American Psychologist, 48(1), 35-44.

Baldwin, J. M. (1894). Personality-Suggestion. Psychological Review, 1, 274-279.

Barsalou, L. W. (2008). Grounded Cognition. Annual Review of Psychology, 59, 617-645.

Barsalou, L. W. (2009). Simulation, situated conceptualisation, and prediction. Philosophical Transcactions of the Royal Society B, 364, 1281-1289.

Billett, S. (1994). Situated Learning - a workplace experience. Australian Journal of Adult and Community Education, 34(2), 112-130.

Billett, S. (2001a). Knowing in practice: Re-conceptualising vocational expertise. Learning and Instruction, 11(6), 431-452.

Billett, S. (2001b). Learning in the workplace: Strategies for effective practice. Sydney: Allen and Unwin.

Billett, S. (2003). Sociogeneses, Activity and Ontogeny. Culture and psychology, 9(2), 133-169.

Billett, S. (2006). Relational interdependence between social and individual agency in work and working life. Mind, Culture and Activity, 13(1), 53-69.

Billett, S. (2008). Learning throughout working life: A relational interdependence between social and individual agency British Journal of Education Studies, 55 (1), 39-58.

Billett, S. (2009a). Conceptualising learning experiences: Contributions and mediations of the social, personal and brute. Mind, Culture and Activity, 16(1), 32-47.

Billett, S. (2009b). Personal epistemologies, work and learning. Educational Research Review, 4 210-219.

Billett, S. (2009c). Realising the educational worth of integrating work experiences in higher education. Studies in Higher Education, 34 (7), 827-843.

Billett, S. (2011). Curriculum and pedagogic bases for effectively integrating practice-based experiences. Sydney: Australian Learning and Teaching Council,.

Billett, S. (2013). Recasting transfer as a socio-personal process of adaptable learning. Educational Research Review 8,, 5-13. 
Billett, S., Sweet, L., \& Glover, P. (2013). The curriculum and pedagogic properties of practicebased experiences: The case of midwifery students. Vocations and Learning: Studies in Professional and Vocational Education, 6 (2 ), 237-258.

Brown, J. S., Collins, A., \& Duguid, P. (1989). Situated Cognition and the Culture of Learning. Educational Researcher, 18(1), 32-34.

Chi, M. T. H., Feltovich, P. J., \& Glaser, R. (1981). Categorisation and representation of physics problems by experts and novices. Cognitive Science, 5, 121-152.

Coll, R. K., \& Zegwaard, K. E. (2011). International Handbook for Cooperative \& Work-integrated Education. Retrieved from

Deissinger, T. (2002). Apprenticeship systems in England and Germany: decline and survival. Paper presented at the Towards a history of vocational education and training (VET) in Europe in a comparative perspective, Florence.

Department of Innovation, U. a. S. (2008). Higher education at work: . Department of Innovation, Universities and Skills.

Eames, C., \& Coll, R. (2010). Cooperative Education: Integrating Classroom and Workplace Learning. In S. Billett (Ed.), Learning through practice (pp. 180-196). Dordrecht: Springer.

Elias, J. L. (1995). Philosophy of education: classical and contemporary. Malabar, Florida: Krieger Publishing.

Ericsson, K. A. (2006). The Influence of Experience and Deliberate Practice on the Development of Superior Expert Performance. In K. A. Ericsson, N. Charness, P. J. Feltowich \& R. R. Hoffmann (Eds.), The Cambridge Handbook of Expertise and Expert Performance (pp. 685705). Cambridge: Cambridge University Press.

Ericsson, K. A., \& Lehmann, A. C. (1996). Expert and exceptional performance: Evidence of maximal adaptation to task constraints. Annual Review of Psychology, 47, 273-305.

Gardner, H. (2004). What we do \& don't know about learning. Daedalus, 133(1), 5-12.

Gergen, K. J. (1994). Realities and relationships: Soundings in social construction. Cambridge, Mass, Harvard University Press.

Giddens, A. (1991). Modernity and self-identity: Self and society in the late modern age. Stanford: Stanford University Press.

Glenberg, A. M., Schroeder, J. L., \& Robertson, D. A. (1998). Averting the gaze disengages the environment and facilitates remebering. Memory and Cognition, 26(4), 651-658.

Griffiths, T., \& Guile, D. (2003). A connective model of learning: The implications for work process knowledge. . European Educational Research Journal,. 2(1 ), 56-73.

Grollman, P., \& Tutschner, R. (2006). Possible intended and unintended effects of European VET policies - The case of integrating work and learning. Paper presented at the European Research Network in Vocational Education and Training Symposium, Geneva.

Grubb, W. N., \& Badway, N. (1998). Linking School-Based and Work-Based Learning: The Implications of LaGuardia's Co-op Seminars for School-to-Work Programs (pp. 1-30). Berkeley: National Center for Research in Vocational Education

Guile, D., \& Young, M. (2003). Transfer and transition in vocational education: Some theoretical considerations. In T. Tuomi-Grohn \& Y. Engestrom (Eds.), Between school and work: New perspectives on transfer and boundary crossing (pp. 63-81). New York: Pergamon.

Heikkinen, H. L. T., Tynjälä, P., \& Kiviniemi, U. (2011). Integrative pedagogy in practicum: Meeting the second order paradox in teacher education In M. Mattson, T. V. Eilertsen \& D. Rorrison (Eds.), A practicum turn in teacher education. Rotterdam: Sense.

Hodges, D. C. (1998). Participation as dis-identification with/in a community of practice. Mind, Culture and Activity, 5(4), 272-290.

Lave, J. (1991). Situating Learning in Communities of Practice. In L. B. Resnick, J. M. Levine \& S. Teasley (Eds.), Perspectives on Socially Shared Cognition (pp. 63-82). Washington, D. C: American Psychological Association.

Lee, Y. J., \& Roth, W.-M. (2005). The (unlikely) trajectory of learning in a salmon hatchery. Journal of Workplace Learning., 17, 243-254. 
Luria, A. R. (1976). Cognitive development: its cultural and social foundations. Cambridge, Mass: Harvard University Press.

Malle, B. F., Moses, L. J., \& Baldwin, D. A. (2001). Introduction: The Significance of Intentionality. In B. F. Malle, L. J. Moses \& D. A. Baldwin (Eds.), Intentions and Intentionality: Foundations of Social Cognition (pp. 1-26). Cambridge, Massachusetts: The MIT Press.

Marsick, V. J., \& Watkins, K. (1990). Informal and incidental learning in the workplace. London: Routledge.

Miller, P. J., \& Goodnow, J. J. (1995). Cultural practices: Towards an integration of culture and development. In J J Goodnow, P. J. Miller \& F. Kessel (Eds.), Cultural Practices as Contexts for Development (Vol. 67, pp. 5-16). San Francisco: Jossey Bass.

Newton, J., Billett, S., \& Ockerby, C. (2009). Journeying through clinical placements - an examination of six student cases. . Nursing Education Today 29 (6), 630-634.

Newton, J., Kelly, C., Kremser, K., Jolly, B., \& Billett, S. (2009). The motivations to nurse: an exploration of factors amongst undergraduate students, registered nurses and nurse managers,. Journal of Nursing Management, , 17 (3), 392-400.

Organisation for Economic Co-operation and Development. (2010). Learning for jobs. Paris: OECD.

Papadopoulos, D. (2008). "In the ruins of representation: identity, individuality, subjectification." British Journal of Social Psychology 47(139-165).

Perkins, D. (1997). Person-plus: a distributed view of thinking and learning. In G. Salomon (Ed.), Distributed Cognitions: Psychological and educational considerations (pp. 88-110). Cambridge: Cambridge University Press.

Perkins, D., Jay, E., \& Tishman, S. (1993). Beyond abilities: A dispositional theory of thinking. Merrill-Palmer Quarterly, 39(1), 1-21.

Piaget, J. (1968). Structuralism (C. Maschler, trans. and ed.). London: Routledge \& Kegan Paul.

Raizen, S. A. (1989). Reforming education for work: A cognitive science perspective. Berkeley C A: National Centre for Research in Vocational Education.

Ricks, F. (1996). Principles for Structuring Cooperative Education Programs. Journal of Cooperative Education, 31(2-3), 8-22.

Rogoff, B., \& Lave, J. (Eds.). (1984). Everyday cognition: Its development in social context. Cambridge, Mass: Harvard University Press.

Roth, W. M., \& Roychoudhury, A. (1993). The concept map as a tool for the collaborative construction of knowledge: A microanalysis of high school physics students. Journal of Research in Science Teaching, 30(5), 503-534.

Schutz, A. (1970). On phenomenology and social relations (ed Helmut Wagner). Chicago: University of Chicago Press.

Scribner, S. (1984). Studying working intelligence. In B. Rogoff \& J. Lave (Eds.), Everyday cognition: Its development in social context (pp. 9-40). Cambridge, Mass: Harvard University Press.

Smagorinsky, P. (2011). Vygotsky and Literacy Research: A Methodological Framework Rotterdam: Sense Publishers.

Stenstrom, M.-L., Grollman, P., Tutschner, R., Tynjala, P., Nikkanen, \& Loogma, K. (2006). Integration of work and learning: Policies, strategies and practices Paper presented at the European Research Network in Vocational Education and Training Symposium, Geneva.

Stevenson, J. C. (1991). Cognitive structures for the teaching of adaptability in vocational education. In G. Evans (Ed.), Learning and teaching cognitive skills (pp. 144-163). Victoria, Australia: ACER.

Symonds, W. C., Schwartz, R. B., \& Ferguson, R. (2011). Pathways to prosperity: Meeting the challenge of preparing young people for the 21st century. Cambridge, MA: Harvard Graduate School of Education. 
Tobias, S. (1994). Interest, prior knowledge, and learning. Review of Educational Research, 64(1), 37-54.

Tuomi-Grohn, T., \& Engestrom, Y. (Eds.). (2003). Between school and work: New perspectives on transfer and boundary crossing. New York: Pergamon.

Tynjala, P. (2008). Perspectives into learning in the workplace. Education Research Review, 3(2), 130-154.

Tynjälä, P., Välimaa, J., \& Sarja, A. (2003). Pedagogical perspectives into the relationship between higher education and working life. Higher Education, 46, 147-166.

Universities Australia. (2008). A National Internship Scheme: Enhancing the skills and workreadiness of Australian university graduates Canberra: Universities Australia.

Valsiner, J. (1998). The guided mind: A sociogenetic approach to personality. Cambridge, Mass: Harvard University Press.

Valsiner, J. (2000). Culture and human development. London: Sage Publications.

Valsiner, J., \& van der Veer, R. (2000). The social mind: The construction of an idea. Cambridge, UK: Cambridge University Press.

Van Lehn, V. (1989). Towards a theory of impasse-driven learning. In H. Mandl \& A. Lesgold (Eds.), Learning issues for intelligent tutoring systems (pp. pp. 19-41). New York: SpringerVerlag.

von Glasersfeld, E. (1987). Learning as a constructive activity. In C. Janvier (Ed.), Problems of representation in the teaching and learning of mathematics (pp. 3-17). Hillsdale, NJ: Lawrence Erlbaum.

Voss, J. F. (1987). Learning and transfer in subject matter learning: a problem-solving model. International Journal of Educational Research, 11(6), 607-622.

Wertsch, J., \& Tulviste, P. (1992). L. S. Vygotsky and contemporary developmental psychology. . Developmental Psychology, , 28(4), 548-557.

Wertsch, J. V., \& Tulviste, P. (1992). L. S. Vygotsky and contemporary developmental psychology. Developmental Psychology, 28(4), 548-557.

Wertsch, J. W. (1991). A sociocultural approach to socially shared cognition. In L. B. Resnick, J. M. Levine \& S. D. Teasley (Eds.), Perspectives on socially shared cognition (pp. 85-100). Washington DC: American Psychological Association. 